\title{
Conectando problemas, soluções e expectativas: mapeando a literatura sobre análise do desenho de políticas públicas
}

\author{
Luciana Leite Lima' \\ Rafael Barbosa de Aguiar ${ }^{2}$ \\ Lizandro Lui ${ }^{3}$
}

DOI: 10.1590/0103-3352.2021.36.246779

\section{Introdução ${ }^{4}$}

O atual campo de estudos sobre desenho de políticas públicas foi catalisado pela proposição de Linder e Peters (1988). Os autores sugeriram uma distinção analítica entre ( $i$ ) o processo de elaboração dos desenhos e (ii) o conceito de desenho. O primeiro abarca o processo de formulação dos desenhos e está focado na tomada de decisão, especialmente do ponto de vista da atividade política, do conflito entre atores, ideias e interesses; já o desenho, entendido como conteúdo das políticas, enfatiza seus elementos formadores, características, implicações, interações e relações com os contextos de governança (SIDDIKI, 2020).

1 Professora da Universidade Federal do Rio Grande do Sul (UFRGS), Programa de Pós-Graduação em Políticas Públicas, Porto Alegre, RS, Brasil. E-mail: Iucianaleitelima@gmail.com

2 Doutorando em Políticas Públicas da Universidade Federal do Rio Grande do Sul (UFRGS), Programa de PósGraduação em Políticas Públicas, Porto Alegre, RS, Brasil. E-mail: rafaelba@yahoo.com.br

3 Professor da Fundação Getúlio Vargas (FGV), Escola de Políticas Públicas e Governo, Brasília, DF, Brasil. E-mail: lizandrolui@gmail.com

4 Agradecemos os comentários e sugestões das(os) pareceristas anônimas(os) da Revista Brasileira de Ciência Política. Qualquer equívoco ou omissão é responsabilidade exclusiva da e dos autores. 
Essa distinção propiciou o desenvolvimento da perspectiva do desenho, focada na análise dos aspectos substantivos, isto é, dos elementos que formam o conteúdo das políticas, os quais traçam sua estrutura e dinâmica (HOWLETT, 2011a; HOWLETT; MUKHERJEE; WOO, 2015; PETERS, 2015). Especificamente, entende-se que as formas empíricas das políticas públicas (leis, estatutos, regras administrativas, por exemplo) contêm elementos comuns, que correspondem à sua estrutura lógica, são eles: problemas e objetivos, instrumentos de implementação, beneficiários e regras de inclusão/exclusão, sistema de governança, racionalidades e construções sociais (HOWLETT, 2018a; LINDER; PETERS, 1990; ROGGE, 2018; SCHNEIDER, 2015). O campo se volta, então, para a análise de cada um desses elementos, das relações entre eles e de suas interações com os contextos institucionais, políticos e organizacionais.

Essa literatura assume que a qualidade do desenho é uma variável relevante para o melhor desempenho das políticas, acompanhando argumentos encontrados nos estudos de implementação e de avaliação (BARDACH, 1980; HOWLETT, 2019; SABATIER; MAZMANIAN, 1980; SCHNEIDER; INGRAM, 1988; VEDUNG, 2015). Ainda, afirma-se que o propósito desse tipo de estudo é contribuir para a qualificação do policy-making, das políticas e de seus resultados (COMPTON; LUETJENS; HART, 2019; HOWLETT, 2011a; HOWLETT; MUKHERJEE; RAYNER, 2018; LINDER; PETERS, 1990), o que demonstra o alinhamento às ideias fundadoras da policy analysis (COLEBATCH, 2018; HOWLETT; LEJANO, 2012).

Ao longo deste artigo, evidenciaremos que a produção internacional sobre policy design vem avançando nas últimas décadas e que no Brasil, contudo, ainda é incipiente. E, tendo em vista o direcionamento dessa literatura para entender e qualificar as políticas e o diagnóstico de que essas questões são centrais também no Brasil (GOMES, 2019; JANNUZZI, 2016), argumentamos que uma sistematização abrangente pode contribuir para o desenvolvimento do campo da análise de políticas públicas brasileiro.

Desse modo, empreendemos uma revisão da literatura do campo de policy design com foco na perspectiva do desenho. Esse tipo de estudo permite compreender a estrutura intelectual de um campo, entendida como o "conjunto de atributos salientes da base de conhecimento que pode fornecer uma 
estrutura organizada e compreensão holística do domínio científico escolhido" (SHAFIQUE, 2013, p. 62, tradução nossa). Portanto, o objetivo é sistematizar o conhecimento, fornecendo um mapa da literatura, identificando os temas que recebem atenção, bem como aqueles menos abordados, e, nesse caminho, são debatidos conceitos e perspectivas. De forma mais ampla, o intuito é formar a base para o desenvolvimento de uma agenda de pesquisa que acione os conceitos e as abordagens propostas, assim como estimular o engajamento do campo de públicas com a temática.

Para tanto, o texto está estruturado da seguinte forma: o tópico que segue localiza o policy design nas policy sciences; a seguir, apresentamos os procedimentos metodológicos; o subsequente traz a discussão sobre o conceito de desenho; depois, abordamos cada um dos elementos que formam o desenho, conforme especificado na literatura; em seguida, discutimos alguns trabalhos nacionais que se aproximam dessa literatura e delineamos uma agenda de pesquisa; por fim, nas considerações finais, sistematizamos as ideias e expomos as limitações deste trabalho.

\section{Policy sciences e policy design}

O campo do desenho das políticas públicas situa-se no domínio das policy sciences (HOWLETT; LEJANO, 2012), constituindo uma das abordagens para o estudo do policy process (SABATIER, 2007). O termo policy sciences foi cunhado por Harold Lasswell em 1951 e designa o estudo das políticas públicas como uma ciência aplicada. Nesse intento, ele propôs observar as políticas como um processo (policy process), "isto é, um conjunto inter-relacionado de estágios por meio dos quais os temas e as deliberações fluem de forma mais ou menos sequencial, dos inputs (problemas) aos outputs (políticas públicas)" (HOWLETT, 2011a, p. 18, tradução nossa). Com isso, pretendia integrar aspectos da formulação e da implementação, dando atenção especial aos instrumentos das políticas. Tal orientação marcou os estudos subsequentes, que passaram a investigar os múltiplos meios pelos quais os governos poderiam afetar as policies e os contextos em que poderiam ser usados (HOWLETT, 2011b). De forma relacionada, Lasswell preocupou-se com o incremento do policy process e das políticas resultantes de forma que pudessem funcionar diante dos constrangimentos dos sistemas políticos (PETERS; RAVA, 2017). 
De acordo com Siddiki (2020), é dessa procedência que decorre o uso multidisciplinar, principalmente pela ciência política, administração pública e economia. Ele situa o início do desenvolvimento da área na década de 1960, quando a distinção entre desenho e processo de formulação ainda não havia sido proposta. Nesse momento, as perspectivas teóricas manejadas por estudiosos provinham daquelas disciplinas, com destaque para a teoria da escolha pública. Também eram usadas as tipologias de Lowi (1964) e de Wilson (1974) - a primeira classifica as políticas com base no tipo de atividade política que suscitam; a segunda, desde a distribuição de custos e benefícios entre os grupos sociais. A partir da década de 1980, a separação analítica entre desenho e processo começa a marcar a área e duas teorias passam a ser mais acionadas: Social Construction Theory, delineada por Anne Larason Schneider e Helen Ingram (SCHNEIDER; INGRAM, 1997), e Institutional Analysis and Development Framework, desenvolvida por Elinor Ostrom e outros (OSTROM, 2005). Em seu trabalho, Schneider e Ingram especificam e desenvolvem a distinção analítica entre desenho e processo. Desde então, tais autoras se mantêm entre as mais citadas da área.

Em termos de contexto empírico, a literatura de policy design oferece a possibilidade de utilização de uma série de ferramentas e instrumentos que podem ser aplicados a diferentes tipos de políticas. Por ser um campo de estudos multidisciplinar, diversas áreas, como ciência política, administração pública, economia, análise de decisão, ciências da natureza e pesquisa operacional, já abordaram a temática (PLUCHINOTTA et al., 2020). Por exemplo, Zhang e colaboradores (2015) usaram a Social Construction Theory para analisar protestos em massa; Snow (2019) investigou políticas de medicina neuropática; Al-Kohlani e Campbell (2016), as políticas de qualidade do ar; Siddiki (2014) usou a Institutional Analysis and Development Framework para estudar a política de aquacultura.

Por fim, parece pertinente apontar como essa área se relaciona com a abordagem analítica mais popular do campo das políticas públicas. Segundo Brasil e Capella (2016), o ciclo de políticas públicas é um recurso metodológico cujo objetivo é oferecer uma visão em etapas das políticas, simplificando a complexidade do fenômeno. Como veremos, a abordagem do desenho de políticas públicas é mais fluida e não se baseia na ideia de etapas. Com efeito, 
pode-se abordar, por exemplo, processos de formulação, versando sobre as diferentes formas que assumem, a depender das racionalidades subjacentes e das intencionalidades. Sobre isso, historicamente, as policy sciences têm enfocado uma variedade de tipos de formulação de políticas (HOWLETT, 2020), desde as baseadas no conhecimento até as orientadas por negociação legislativa, promoção clientelista e esquemas que incorporam vantagem eleitoral partidária (HOWLETT, 2020). Esses últimos, apesar de serem considerados esforços para formular alternativas de política, não se assemelham ao que comumente se entende por "design", em função de sua intencionalidade, sendo, portanto, referidos como "não design" (HOWLETT; MUKHERJEE, 2014). Ainda, a abordagem do desenho é acionada para analisar a implementação, por meio do exame dos instrumentos de execução das políticas, uma das linhas mais profícuas. Em uma utilização mais compreensiva, pode ser usada para investigar a estrutura lógica das políticas, como a coerência entre seus objetivos, a consistência dos instrumentos e a congruência entre ambos os elementos (VAN GEET; LENFERINK; LEENDERTSE, 2019). Tais usos serão explicitados nos tópicos que seguem.

\section{Procedimentos metodológicos}

Esta é uma pesquisa exploratória e descritiva, pois pretende produzir informações sobre o campo de estudos de policy design. Para tanto, adotamos como procedimento a revisão de literatura, útil quando o pesquisador deseja avaliar a teoria ou a evidência em uma determinada área ou examinar a validade ou precisão de dada teoria ou teorias concorrentes (TRANFIELD; DENYER; SMART, 2003). Snyder (2019, p. 334, tradução nossa) considera-as relevantes "quando o objetivo é fornecer uma visão geral de um determinado assunto". Nesse sentido, as revisões de literatura se ajustam a estudos que buscam avaliar o estado do conhecimento sobre um determinado tópico, visando criar agendas de pesquisa, identificar lacunas no campo, discutir um assunto específico e aumentar o engajamento (BAUMEISTER; LEARY, 1997; SNYDER, 2019; TORRACO, 2005).

A abordagem empregada é a revisão semissistemática, ou narrativa (SNYDER, 2019), que apresenta a posição de vários estudiosos de forma crítica, o que permite detectar temas, perspectivas, questões comuns, emergentes 
ou negligenciadas dentro do campo mapeado (WARD; HOUSE; HAMER, 2009). Quanto à estratégia de coleta de dados, utilizamos a snowball sampling, adequada para "buscar referências de referências e rastreamento eletrônico de citações, sendo especialmente poderosa para identificar fontes de alta qualidade em locais obscuros" (GREENHALGH; PEACOCK, 2005, p. 1065, tradução nossa). Ela consiste em "uma forma de amostra não probabilística utilizada em pesquisas sociais onde os participantes iniciais de um estudo indicam novos participantes [...] e assim sucessivamente", até que seja alcançado o objetivo proposto ou o ponto de saturação (BALDIN; MUNHOZ, 2011). O ponto de saturação é atingido quando as fontes passam a repetir os conteúdos, sem acrescentar novas informações relevantes à pesquisa. Portanto, a snowball sampling é uma técnica de amostragem que utiliza cadeias de referência, formando uma rede. Assim, o primeiro passo é definir a fonte inicial da busca e, subsequentemente, ir formando uma rede de fontes até o ponto de saturação.

Neste trabalho partimos do estudo seminal de Michael Howlett (2011b), a fim de rastrear as citações/referências sobre o campo do policy design, o que nos levou à próxima fonte, e assim sucessivamente, até termos uma amostra suficientemente satisfatória. O rastreio consistiu no exame das listas de referências e no julgamento da inclusão ou não na amostra (GREENHALGH; PEACOCK, 2005). Foram coletadas fontes secundárias, especificamente: papers, artigos, livros e capítulos de livros. Foram incluídos aqueles que estavam disponíveis on-line e gratuitos, bem como livros que puderam ser adquiridos. A coleta foi realizada entre dezembro de 2019 e abril de 2020 e foram recolhidos, ao todo, 74 documentos, sendo: 3 papers, 36 artigos, 14 livros e 21 capítulos de livros.

Por fim, o material foi lido e submetido à análise de conteúdo indutiva com o auxílio do software NVivo. Tal análise deve ser conduzida quando o fenômeno a ser estudado é fragmentado (LAURI; KYNGÄS, 2005). Seguindo Elo e Kyngäs (2008), o processo de organização dos dados abarcou três etapas: codificação aberta, criação de categorias e abstração. A primeira fase consistiu em escrever notas no texto durante a leitura, criando livremente os nós das categorias. Após essa codificação aberta, as listas de categorias foram agrupadas, com o objetivo de reduzir seu número, isto é, juntando aquelas que são semelhantes em categorias mais amplas (BURNARD, 1991; DEY, 1993; DOWNEWAMBOLDT, 1992). A segunda etapa consistiu na criação de grupos. Para o 
presente estudo, trabalhamos inicialmente com as categorias: (i) conceito de policy design; (ii) perspectivas de análise; e (iii) elementos do desenho. E, por último, a abstração, processo que abrange a nomeação de cada categoria usando palavras características do conteúdo. Subcategorias com eventos semelhantes são agrupadas como categorias e categorias são agrupadas como categorias principais (DEY, 1993; ROBSON, 2002). O processo de abstração "continua na medida do razoável e possível” (LAURI; KYNGÄS, 2005, p. 111, tradução nossa). Nesse sentido, (ii) foi incorporada nas demais e (iii) foi desmembrada em problema, objetivo, instrumentos, target groups e resultados.

\section{Desenho: conceito e dimensões relacionadas}

Como mencionamos, este trabalho aborda a perspectiva que define o desenho como o conteúdo das políticas. A partir dessa concepção, a seguir, discutiremos o conceito de desenho e suas dimensões.

A definição de policy design exibe um alto nível de congruência na produção do campo. De forma geral, a literatura apresenta o desenho como um conjunto lógico de elementos cuja construção foi proposital, possuindo, dessa forma, finalidade explícita. Ilustrativamente: policy design envolve a tentativa deliberada de definir objetivos e conectá-los com instrumentos que possam cumpri-los (HOWLETT; MUKHERJEE; WOO, 2015); policy design é uma abordagem direcionada ao desenvolvimento de soluções para problemas sociais, portanto, espera-se que a solução seja criada com vistas a atingir um dado objetivo (JUNJAN, 2020); desenhar uma política envolve reconhecer a existência de um problema público, tentar entender a sua dinâmica e, a partir daí, delinear uma solução (PETERS, 2020a); o desenho tem a ver com boas ideias acerca do que o problema é e sobre como lidar com ele da melhor forma, além disso, trata da escolha dos instrumentos e sua adequação aos contextos de ação (LINDER; PETERS, 1990); o design envolve invenção consciente, desenvolvimento e aplicação de padrões de ação na resolução de problemas (DRYZEK; RIPLEY, 1988).

A partir desses conceitos podemos explorar algumas dimensões relacionadas. Comecemos com a questão da finalidade do desenho. Como se vê, a preocupação com os resultados das políticas é persistente nas definições: em uma perspectiva de desenho, a formulação deve atentar para a efetividade da 
implementação (HOWLETT, 2019). Para Howlett e Mukherjee (2018), a efetividade é o objetivo fundamental de qualquer desenho, sendo entendida como a capacidade da política de atingir seus objetivos. Tal acepção pode ser observada nas palavras de Howlett, empreendedor e prolífico pesquisador do campo: policy designs podem ser pensados como configurações ideais de conjuntos de elementos dos quais se pode esperar que, razoavelmente, gerem um resultado específico em um dado contexto de governança (HOWLETT, 2011b).

Esse tipo de discussão vem acompanhado da indicação dos fatores que podem limitar a efetividade. Peters (2020b), por exemplo, assinala a setorialidade organizacional e a complexidade dos problemas sociais como complicadores. Já Chindarkar, Howlett e Ramesh (2017) apontam as capacidades política e técnica dos governos. A primeira diz respeito à capacidade de governança da diversidade de atores e dos espaços organizacionais, o que influencia o acesso a recursos e a conformidade com as políticas. A segunda remete à habilidade analítica-organizacional, abrangendo coleta, análise, armazenamento e disseminação de informação.

De outro ângulo, Schneider e Ingram (1997) propuseram uma abordagem que se tornou uma das mais influentes no campo. As autoras sustentam que os desenhos têm consequências sociais e políticas: na identidade social dos beneficiários, nas suas oportunidades de participação e na avaliação que fazem do Estado. Desse modo, os seus resultados devem ser analisados considerando-se o impacto na promoção da democracia. Nesse caminho, seus trabalhos ressaltam os efeitos das características e das configurações dos desenhos para os grupos vulneráveis, investigando as racionalidades subjacentes, as imagens da realidade que acionam e operam, bem como as relações entre a modelagem de problemas, os objetivos e os instrumentos (INGRAM; SCHNEIDER; DELEON, 2007).

Outro elemento perceptível nos conceitos é o da centralidade do uso do conhecimento, característica que diferenciaria o design de outras maneiras de formulação (HOWLETT, 2019) e que explicita a racionalidade valorizada no campo. O conhecimento pode ser proveniente da experiência, de sucessos e fracassos passados e de boas práticas (HOWLETT, 2019); também da investigação criteriosa dos problemas e dos impactos dos instrumentos no comportamento dos agentes (HOWLETT; MUKHERJEE; WOO, 2015). Para Dryzek 
e Ripley (1988), o desenho requer dois tipos de teoria: empírica, sobre os efeitos da política; e normativa, que avalia os efeitos e os processos em termos de valores e interesses promovidos, obstruídos, violados ou ignorados.

No entanto, a orientação baseada no conhecimento encontra obstáculos. Howlett e Mukherjee (2018) ponderam que desenhar uma política é difícil por várias razões: escassez de recursos, ineficiência burocrática, presença de veto players poderosos, definição de objetivos vagos, implementação e avaliações falhas, entre outras. Nessas circunstâncias, o grau com que o processo é informado pelo conhecimento e pela evidência depende fortemente do ambiente político (HOWLETT; MUKHERJEE, 2018) e da percepção popular sobre o problema em foco (CHINDARKAR; HOWLETT; RAMESH, 2017). Ainda, Howlett e Mukherjee (2018) alegam que uma prática comum é a busca e o uso de informações que apoiem argumentos e posições previamente desenvolvidos.

O campo endogeniza essas constatações e reafirma a defesa daquela racionalidade com base no seguinte argumento: a aplicação de conhecimento e análise à criação de políticas conduz a opções mais capazes de lidar com problemas sociais do que aquelas que emergem de processos de não desenho (HERMUS; VAN BUUREN; BEKKERS, 2020; HOWLETT, 2019). Isso ganha contornos especiais com a emergência dos wicked problems e a consequente necessidade de qualificar as políticas (CHINDARKAR; HOWLETT; RAMESH, 2017). Sobretudo, entende-se que os cidadãos esperam que os formuladores de políticas baseiem suas decisões em critérios lógicos e transparentes, em conhecimento e experiência, em vez de motivações puramente individuais e preconceitos (HOWLETT; MUKHERJEE; WOO, 2015).

Isso nos leva a outro aspecto do conceito: a instrumentalidade. Conforme Hermus, van Buuren e Bekkers (2020), o policy design é instrumental no sentido em que conecta problemas com soluções; o que está associado ao tipo de racionalidade presente nos processos: orientada pelo conhecimento e pela lógica. Desse tema emerge uma questão bastante presente na literatura, nas palavras de Chindarkar, Howlett e Ramesh (2017): equilibrar objetivos políticos e técnicos é um dos desafios do desenho de políticas públicas. A dimensão política se refere à natureza institucional e partidária do contexto no qual as políticas são decididas; e a dimensão técnica, às capacidades orientadas pelo 
conhecimento sobre os elementos do desenho e seu impacto nos beneficiários (CAPANO; HOWLETT, 2021). A relação entre elas embasa a diferenciação entre desenho, não desenho e antidesign.

A orientação para o desenho exibe direcionamento instrumental, preocupada com a conexão entre objetivos e instrumentos de forma a modificar a estrutura e/ou dinâmica dos problemas. Aqui o desenho corresponde a um tipo de formulação baseada no uso e na produção de conhecimento sobre os problemas e sobre os efeitos dos instrumentos na população beneficiária, e na aplicação desse conhecimento para desenvolver e implementar políticas que atinjam os objetivos almejados (CHINDARKAR; HOWLETT; RAMESH, 2017; HOWLETT; MUKHERJEE, 2018; LINDER; PETERS, 1989). Tal direcionamento, segundo Dryzek e Ripley (1988), ofereceria um alto grau de abertura e publicidade ao processo.

Esse tipo de desenho abarca desde os modelos mais fortemente guiados pela lógica científica, como os baseados em evidências, passando pelos que enfocam o papel da criatividade e da inovação, propondo soluções centradas nos usuários, até dinâmicas ao estilo garbage can (HERMUS; VAN BUUREN; BEKKERS, 2020; HOWLETT; MUKHERJEE, 2018). Isso porque nestas proposições a ideia é gerar desenhos que exibam conexões entre seus elementos e que possam sobreviver à avaliação pública.

Já a perspectiva de não desenho corresponde a maneiras de formulação caracterizadas pela contingência, tais como: barganha, log-rolling, clientelismo, bureaucratic politics, blame avoidance e outras maneiras de gerar alternativas que sejam dirigidas por heurísticas comportamentais (HOWLETT, 2019). Ou seja, mesmo que tais processos promovam a elaboração de alternativas, elas são caracterizadas por muita inconsistência e incoerência entre seus elementos (CHINDARKAR; HOWLETT; RAMESH, 2017). Nesse tipo de processo, a preocupação central é harmonizar interesses, minimizar conflitos, alcançar o consenso possível; ou seja, a orientação para lidar com um problema é secundária.

O conceito de antidesign, por sua vez, tange à desconexão entre problemas, intervenções e resultados. Tal incongruência pode estar relacionada à incompetência, corrupção e tendências econômicas globais, além de atividade política disfuncional. Nesse contexto, os problemas sociais não estão definidos, 
os objetivos não se articulam e os resultados são irrelevantes, já que desconectados de qualquer propósito. O conceito foi desenvolvido por Newman e Nurfaiza (2020), que o utilizaram para analisar a política de regulação dos cigarros eletrônicos na Indonésia. Os autores encontram um cenário de formulação desprovido de racionalidade identificável: "observando os detalhes da intervenção indonésia, é difícil entender qual era a intenção da política ou quais os resultados ela deveria alcançar" (NEWMAN; NURFAIZA, 2020, p. 13, tradução nossa).

Essas distinções desvelam o debate em torno do lugar da atividade política nos processos de desenho. Howlett (2019), por exemplo, sustenta que, em uma perspectiva de não desenho, é mais provável que se promovam políticas que não funcionem bem, com alto grau de ambiguidade em seus elementos, que alocam recursos para atividades menos programáticas e, fazendo isso, fracassam em lidar com problemas coletivos. De outro modo, Chindarkar, Howlett e Ramesh (2017) alertam para as limitações tanto de formulações populistas quanto das tecnocráticas. No primeiro tipo tem-se a busca de objetivos políticos desacompanhada da intenção de enfrentar problemas públicos; e, no segundo, medidas que tentam enfrentar problemas sem considerar as implicações políticas.

De forma semelhante, Junjan (2020) adverte que a dimensão política é intrínseca às atividades orientadas para o encaminhamento de problemas coletivos, já que envolve uma multiplicidade de atores. Tal característica, por sua vez, carrega conflito, já que expõe e mobiliza valores sociais e interesses em um processo de decisão sobre a delimitação de um problema social, as evidências a serem usadas para entendê-lo e para construir as alternativas, os objetivos e os instrumentos de implementação. Dessa maneira, as arenas que se formam em subsistemas de políticas conformam os contextos de governança nos quais uma pluralidade de atores promove esforços para lidar com problemas e atingir objetivos (HOWLETT, 2011b). A pluralização do policy-making se expressa nas novas organizações voltadas à coprodução, cocriação e codesign, que pretendem incluir diferentes atores no desenvolvimento de respostas a problemas complexos (McGANN; WELLS; BLOMKAMP, 2021).

Nesse ponto, a literatura se volta para o contexto de ação (COMPTON; LUETJENS; HART, 2019; HERMUS; VAN BUUREN; BEKKERS, 2020). De 
Vries, Nemec e Junjan (2020), por exemplo, propõem o conceito de arquitetura da escolha para abordar o contexto no qual o desenho acontece, sendo os fatores mais relevantes o regime político, as relações intergovernamentais, a estrutura organizacional, a cultura organizacional e os valores e inclinações individuais. Já Peters (2020a) destaca que as instituições possuem estilos de design: legislativo, burocracias e judiciário desenham políticas de formas diferentes; distinguindo-se, por sua vez, dos policy labs e outros espaços focados na inovação. Por fim, Peters (2020b) e Junjan (2020) ressaltam que as estruturas e dinâmicas organizacionais exibiriam preferências e concepções próprias sobre os problemas e as formas de lidar com eles, o que se institucionaliza nas rotinas, as quais atuam filtrando as opções disponíveis aos decisores.

Ao longo dessa discussão, constatou-se que o conceito de desenho apresenta várias dimensões, as quais oferecem diversas perspectivas para entender, explorar e analisar as políticas. Cabe, agora, aprofundarmo-nos no conceito de desenho enquanto conteúdo das políticas, por meio do estudo dos seus elementos formadores.

\section{Elementos do desenho: problemas, objetivos, instrumentos, be- neficiários e resultados}

Linder e Peters (1990) sustentam que as formas empíricas das políticas contêm elementos comuns que definem quem deve fazer o que, quando, por que, como e com qual propósito; e as relações entre eles conformam a estrutura lógica dos desenhos. Para fins analíticos, Howlett (2011b) identifica os seguintes elementos: objetivos, metas, instrumentos e suas calibragens. Ingram, Schneider, DELEON (2007) e Ingram e Schneider (2008) acrescentam: problemas a serem resolvidos, beneficiários, regras de inclusão e exclusão, racionalidades que justificam a política e estrutura de implementação. Nessa perspectiva, as políticas são vistas como um regime complexo de fins e meios que existe em um arranjo de governance específico e que muda ao longo do tempo (HOWLETT; MUKHERJEE; RAYNER, 2018). Tais regimes são denominados policy mixes (KERN; ROGGE; HOWLETT, 2019).

Os policy mixes mudam por meio de quatro processos (HOWLETT; MUKHERJEE; RAYNER, 2018): (i) layering: quando objetivos e instrumentos são adicionados a um regime existente, gerando incoerência; (ii) drift: quando 
mudam os objetivos, mas não alteram os instrumentos, os quais se tornam incongruentes com os objetivos e, provavelmente, inefetivos para atingi-los; (iii) conversão: quando os instrumentos existentes são usados para atender novos objetivos; e (iv) substituição: quando novos elementos substituem os preexistentes, pode ser um processo gradual ou abrupto. Observando esses processos, percebe-se que a literatura enfoca os mixes por meio de certas características, como coerência, consistência e congruência, tratadas como proxies de robustez (KERN; ROGGE; HOWLETT, 2019).

Esses processos expõem que os desenhos são delineados sobre fundações preexistentes. Com efeito, Howlett, Mukherjee e Rayner (2018) alegam que as decisões, em geral, tratam de remendar ou reestruturar elementos em vez de propor novas alternativas. Segundo eles, o remendo é uma conformação subótima cuja eficácia, contudo, dependeria das capacidades estatais. Com isso, eles atrelam a efetividade da intencionalidade para o desenho às opções disponíveis dadas as características dos contextos de ação. Nessa linha, Peters (2020a) aponta que a maioria das barreiras que se apresentam ao desenho efetivo decorre da tendência das organizações de reproduzir seus padrões de comportamento e valores, tornando-se resistentes à inovação.

Um conceito que tem sido utilizado para entender a configuração dos mixes é o de heurísticas cognitivas, advindo dos trabalhos de Herbert Simon e de Daniel Kahnemann e Amos Tversky (CONSIDINE, 2018; SCHNEIDER; INGRAM, 1990). As heurísticas cognitivas correspondem aos atalhos mentais que atores acionam para tomar decisões, reconhecendo que a racionalidade é limitada. Elas introduzem vieses nas decisões, gerando arranjos incoerentes e/ou inefetivos (SCHNEIDER; INGRAM, 1990).

Com efeito, Considine (2018) argumenta que atores dependem de uma limitada quantidade de princípios heurísticos, que reduzem as tarefas complexas de acessar probabilidades e predizer efeitos. As heurísticas mais comuns são: (i) representação: quando atores estimam a probabilidade de um evento pertencer a uma classe ou grupo, promovendo o agrupamento por similaridade; (ii) disponibilidade: uso de exemplos recentes ou proeminentes que vêm mais facilmente à mente, os quais, em geral, são os mais chamativos e consistentes com preconceitos, estereótipos e tendências; (iii) ancoragem: uso de um ponto de partida conhecido, ao qual vão sendo adicionadas mudanças incrementais; 
(iv) excesso de confiança na previsão de eventos; e (v) correlações ilusórias: fáceis de imaginar, mas que não têm fundamento científico (CONSIDINE, 2018; SCHNEIDER, 2015; SCHNEIDER; INGRAM, 1990). Esta última pode ser ilustrada com o conceito de ideias zumbi, desenvolvido por Peters e Nagel (2020) para se referir à persistência de ideias que têm pouca fundamentação empírica: "ideias que não morrem, independentemente de quantas vezes forem desaprovadas", que persistem mesmo em face das evidências (p. 3, tradução nossa).

Essa exposição mostra a dinâmica dos mixes de elementos, expondo a complexidade e a dependência de trajetória que acompanham os movimentos relacionados. Com essas questões em mente, partimos para a exploração de cada um dos elementos dos desenhos.

\section{Problemas: da construção política à supercomplexidade}

Os problemas sociais ocupam uma posição de destaque na policy analysis. Em sua formação, a orientação para os problemas era uma das características distintivas do campo (DELEON, 2008). Nessa linha, os problemas encontram-se na base dos processos das políticas públicas, cuja função social seria enfrentá-los. Tal direcionamento é também denominado orientação para a resolução de problemas, a qual fica bem explícita na perspectiva do ciclo de políticas públicas, por exemplo (MULLER; SUREL, 2002).

A partir da literatura mapeada, delimitamos algumas ideias que perpassam as discussões sobre os problemas. Em primeiro lugar, embora a literatura localize a construção do problema na base dos processos de desenho, ela não acolhe a relação causal e automática entre problema e solução (HOPPE, 2018; INGRAM; SCHNEIDER; DELEON, 2007; TURNBULL, 2006). Identificou-se que os trabalhos que tomam os problemas como dados tratam sua modelagem como uma dinâmica exógena ao processo de desenho, o que se deve ao foco dos estudos, em geral, voltados aos instrumentos das políticas. Outros se debruçaram especificamente sobre os processos de modelagem dos problemas, argumentando que a concepção resultante influencia a arena de debates em que o problema será alocado e a escolha das alternativas de resposta (HOPPE, 2018; TURNBULL, 2006).

Um segundo ponto relacionado diz respeito à assunção de que problemas sociais são fruto de construção social, ou seja, do esforço de uma diversidade 
de atores em diferentes arenas institucionais. Um recurso crítico neste processo é a atenção dispensada às definições em competição (HILGARTNER; BOSK, 1988). Nessa linha, encontramos algumas definições: os problemas são interpretações de condições subjetivamente definidas como problemáticas e, como tais, demandam algum tipo de ação (INGRAM; SCHNEIDER; DELEON, 2007; PETERS, 2015); são situações que foram rotuladas como problemas em arenas de discurso e de ação pública, definindo-os como prejudiciais (HILGARTNER; BOSK, 1988); ou, ainda, são preocupações que foram atribuídas à deliberação coletiva e cujo enfrentamento envolve recursos coletivos (TURNBULL, 2006).

De forma geral, os trabalhos percebem o processo de construção do problema como um exercício político baseado em valores e enraizado nas diversas condições individuais, sociais e ideológicas (CHINDARKAR; HOWLETT; RAMESH, 2017; INGRAM; SCHNEIDER; DELEON, 2007; PETERS; RAVA, 2017; SANDERSON, 2002; TURNBULL, 2006; VAN BUUREN et al., 2020). $\mathrm{E}$, desse modo, povoado pelas diversas racionalidades que perpassam as diferentes arenas de debate e ação, envolvendo emoções, preconceitos, crenças profissionais, rotinas organizacionais e tendências políticas (HILGARTNER; BOSK, 1988).

Em terceiro lugar, e de forma mais específica, teríamos dois níveis de modelagem: da preocupação ao problema social; e do problema social ao problema de política pública. As duas dinâmicas são exploradas em Hilgartner e Bosk (1988) e Hoppe (2018) - a primeira, especialmente, no trabalho de Kingdon (1995). O primeiro nível de modelagem diz respeito à mudança de status de uma situação, que passa a ser percebida como coletiva e a demandar uma resposta por meio de recursos da sociedade; o segundo nível enfoca a modelagem que torna os problemas sociais passíveis de serem abordados por meio de ações organizacionais. Em relação a esta, ganha relevo o tratamento institucional recebido das organizações especializadas, cujas preferências e valores demarcam o problema de forma que possa ser contido no domínio de uma dada política.

Os dois processos implicam escolhas sobre as dimensões percebidas, em uma tentativa de redução da complexidade, como consequência, tem-se que os entendimentos serão parciais (HOPPE, 2018), e as definições, contestáveis 
(HILGARTNER; BOSK, 1988). E é esse movimento que viabiliza a delimitação do campo das possíveis respostas (PETERS; RAVA, 2017; TURNBULL, 2006), também, das arenas públicas de discurso, pois as dimensões que se sobressaem alocam os problemas em diferentes jurisdições (INGRAM; SCHNEIDER, 2008).

Por fim, a controvérsia em torno da definição do problema social relaciona-se com um atributo fundamental: a complexidade. O tema é tratado, principalmente, por meio do conceito de wicked problem (RITTEL; WEBBER, 1973). Wicked são problemas mal definidos e que se baseiam em julgamentos políticos ilusórios para sua resolução. Algumas propriedades desse tipo de problema são: não há uma formulação definitiva, tampouco regra de parada tanto para o processo de definição quanto para os de resolução; as partes envolvidas não dispõem de poder para estabelecer as regras para o enfrentamento; soluções não podem ser testadas e as ações geram consequências não previstas, assim como novos problemas.

Mais recentemente, Levin e colaboradores (2012) delinearam o conceito de super wicked problems para abordar os problemas ambientais globais. Esse tipo exibe quatro características: o tempo é curto, o problema vai se agravando e o impacto, aumentando de forma a se tornar menos possível modificar sua progressão; aqueles que causam o problema são os mesmos que criam as soluções; os decisores e as autoridades não controlam as decisões requeridas para amenizar as pressões sobre o clima; as preferências dos decisores são inconsistentes com o tempo, isto é, tomam decisões com horizontes temporais curtos e negam as informações e evidências sobre os riscos da inação.

Enfim, tem-se que a construção social dos problemas é um processo altamente politizado, permeado pela pluralidade de preferências, interesses, ideias e valores sociais, bem como pelas limitações cognitivas e informacionais. Do que decorre que sua formatação será sempre parcial, temporária e controversa. Diante disso, cabe investigar como se dá a conexão entre o problema e o objetivo das políticas.

\section{Objetivos: intencionalidades, conflitos e ambiguidades}

A literatura mapeada não devota muita atenção ao tema dos objetivos, suas características e formação. Apenas em Schneider (2015) encontramos uma definição: objetivos se referem aos aspectos intencionais do desenho e indicam 
quais as consequências pretendidas. A autora alerta que a complexidade dos problemas incentiva objetivos latentes e a formulação de objetivos formais restritos e, talvez, incapazes de lidar com o problema. Já Sanderson (2002) trata brevemente da vinculação entre problema e objetivo. Segundo ele, o processo de definição dos objetivos se vale do conhecimento sobre o problema em foco e sobre a efetividade das opções de enfrentamento, o qual deve servir à deliberação dos decisores.

Desse modo, foi possível identificar que quando algum debate sobre objetivos é feito, são mobilizadas, principalmente, as ideias de Lindblom (1959), Lipsky (2010), Wildavsky (2007) e Wilson (2000). Em comum, esses autores ressaltam as características escorregadias do conceito, bem como o conflito e a ambiguidade que marcam as suas formas empíricas.

A saber, o conflito que cerca a delimitação dos objetivos seria causado pelas diversas preferências das e dos atores, que se manifestam ao longo da discussão pública e podem ficar latentes dependendo dos temas em questão (LINDBLOM, 1959). Já a ambiguidade seria gerada pelo caráter idealizado atribuído aos serviços sociais (queremos muitas coisas, e algumas são aspirações ou visões de futuro) e pelo grau de conflito existente no momento da formulação - quanto mais alto, maior o desincentivo à especificação (LIPSKY, 2010). Além disso, Wildavsky (2007) chama atenção para o estabelecimento de objetivos que não podem ser alcançados porque desconectados das habilidades das organizações implementadoras. Tal formulação seria oportunizada pela carência de conhecimento e pela motivação de agradar grupos de apoiadores políticos.

Como consequência desses atributos, os objetivos não cumpririam a função de informar a elaboração de processos e atividades organizacionais, sendo substituídos por outros fundamentos, como pelos imperativos situacionais, pela expectativa dos pares, pela experiência organizacional e pelas normas profissionais (WILSON, 2000). Outro resultado seria o processo de deslocamento e/ou substituição de objetivos: um mecanismo de ajuste promovido pelas organizações para valorizar variáveis que podem controlar, como seus recursos e habilidades, ou substituí-los por metas de produção, por exemplo (WILDAVSKY, 2007).

Com isso, tem-se que o processo de estabelecimento de objetivos é um espaço de interpretação habitado pelas preferências e ideias das e dos atores, 
bem como pelas características das organizações. Sendo assim, aqui também, o processo é altamente politizado. Logo, a forma possível dos objetivos é vaga, parcial, transitória e controversa. Tendo em vista tal formatação, seguimos para o estudo dos instrumentos, cujo alinhamento com os objetivos é constantemente referido, já que tencionam realizá-los.

\section{Instrumentos: conectando objetivos aos resultados}

Os estudos sobre instrumentos formam uma das linhas mais prolíficas do campo do policy design (VAN BUUREN et al., 2020; HOWLETT; LEJANO, 2012). Desde o trabalho hoje considerado clássico de Christopher Hood (HOOD, 1983), a área se desenvolveu elaborando tipologias, perspectivas para escolha e mudança de instrumentos e explorando a atuação de redes de atores vinculados com a defesa de instrumentos específicos. Tal vitalidade é percebida em diversas coletâneas (ELIADIS; HILL; HOWLETT, 2005; PETERS; VAN NISPEN, 1998; SALAMON, 2002a), além de sistematizações em artigos e capítulos de livros (ACCIAI; CAPANO, 2018; CAPANO; HOWLETT, 2020; HOWLETT, 2011a, 2018b, 2018a; HOWLETT; MUKHERJEE; WOO, 2015; PETERS, 2015; VARGAS; RESTREPO, 2019).

Além de ser uma área bem desenvolvida em relação aos demais elementos, a literatura sobre instrumentos ocupa lugar central no campo do policy design. Isso é constatado nos trabalhos que consideram que a análise e a formulação do desenho correspondem ao estudo e à escolha de instrumentos (CHINDARKAR; HOWLETT; RAMESH, 2017). Por exemplo, quando Howlett, Mukherjee e Woo (2015) relatam como se deu o desenvolvimento do campo, eles afirmam que a atual orientação para o desenho foca no melhor entendimento a respeito de como os instrumentos operam em teoria e prática. Sobre isso, Peters (2020a) e Van Buuren e colaboradores (2020) afirmam que o atual campo do policy design está focado excessivamente no desenho e na seleção de instrumentos.

Desse contexto decorre uma lacuna percebida entre a escolha dos instrumentos, os processos de modelagem dos problemas e os objetivos (PETERS; RAVA, 2017; SANDERSON, 2002; VAN BUUREN et al., 2020). Uma questão relevante, já que o conceito de instrumentos indica a relação entre eles. Para Salamon (2002a), por exemplo, os instrumentos são métodos identificáveis 
por meio dos quais a ação coletiva é estruturada para lidar com um problema público. Ou ainda: são dispositivos que guiam o comportamento em direção a certos objetivos; assim, constituem as regras do jogo, são instituições que alinham a ação pública (VARGAS; RESTREPO, 2019). Em uma perspectiva comportamental, os instrumentos são os incentivos ou desincentivos criados no desenho para assegurar que os grupos-alvo ajam conforme os objetivos da política (SCHNEIDER, 2015; SCHNEIDER; INGRAM, 1988). Como também são técnicas por meio das quais governos geram, avaliam e implementam opções de políticas (CAPANO; HOWLETT, 2020), estando conectados aos objetivos (HOWLETT; MUKHERJEE, 2018).

Apesar da presença no interior do conceito, de fato, a literatura não devota muita atenção para problemas e, menos ainda, para os objetivos. Em relação aos problemas, assumir-se-ia que são bem estruturados (PETERS, 2020a), ignorando-se sua natureza política (PETERS; RAVA, 2017). Com isso, eles ganhariam um caráter objetivo, e o processo de escolha de instrumentos se limitaria a selecionar os meios mais adequados (PETERS; RAVA, 2017). E, embora as definições sugiram a relação entre instrumentos e objetivos, a literatura também os toma como dados.

Uma situação diferente é identificada em relação ao tema do comportamento dos grupos-alvo das políticas, pois, uma vez que os instrumentos pretendem afetá-lo, a conformidade se torna uma questão crítica (HOWLETT, 2018a; SCHNEIDER; INGRAM, 1990). Nesse recorte, Schneider e Ingram (1990) elencam alguns motivos que interferem na adesão aos instrumentos: (i) as pessoas entenderem que as normas não se dirigem a elas ou não as autorizam a agir; (ii) elas carecerem de incentivos ou capacidade para tomar as ações necessárias; (iii) discordarem dos valores implícitos nos meios ou fins; (iv) e não restar claro o que deve ser feito e/ou a situação envolver níveis muito altos de incerteza.

Para lidar com essas situações, foram detectadas duas abordagens. Em uma delas temos os trabalhos que utilizam os insights comportamentais e acionam o conceito de nudge (HOWLETT, 2018a; KUEHNHANSS, 2018): mecanismos voltados a orientar as decisões de forma a se ajustarem melhor aos objetivos dos indivíduos, conforme o seu próprio julgamento (THALER, 2019). Uma segunda linha se debruça sobre metodologias participativas e colaborativas 
que integram os afetados pela política nos processos de desenho (McGANN; WELLS; BLOMKAMP, 2021; VAN BUUREN et al., 2020).

Dada a amplitude dos comportamentos que pretende influenciar e dos efeitos desejados, uma vertente profícua dessa literatura se dedica a identificar a variedade de instrumentos disponíveis aos governos. Como resultado, a sistematização em tipologias é um método difundido. Para demonstrar esse desenvolvimento, abordaremos duas propostas que recebem destaque (HOWLETT, 2018b; SALAMON, 2002b). A primeira é a de Christopher Hood (1983), que desenvolveu uma tipologia que classifica os instrumentos com base em quatro tipos de recursos utilizados para sua operação: (i) nodalidade: referente à capacidade dos governos de movimentar informação, devido à sua posição estratégica nas redes sociais; (ii) tesouro: relativo à posse de estoque de recursos fungíveis (passíveis de serem trocados, como dinheiro), provendo capacidade de troca; (iii) autoridade: tange quanto à posse de poder legal, que oferece a habilidade de determinar, de marcar limites, definir padrões, entre outras; (iv) organização: remete à posse de estoque de pessoas qualificadas, equipamentos e materiais, operando de forma processual, controlada e planejada, propiciando habilidade de ação direta.

A segunda tipologia, de Schneider e Ingram (1990), categoriza os instrumentos em cinco tipos com base nas táticas motivacionais subjacentes: (i) instrumentos de autoridade abarcam permissões, proibições ou requerimentos de ação, assumindo que as pessoas são motivadas pelo comprometimento de obedecer às leis; (ii) instrumentos de incentivo são baseados em recompensas tangíveis, positivas ou negativas, admitindo que as pessoas são maximizadoras de utilidade e que a conformidade com a política depende de incentivos externos; (iii) instrumentos de capacidade incluem provisão de informação, treinamento, educação e recursos para geração de capacidades e pressupõem que a conformidade com a política depende da eliminação das barreiras geradas pela falta de informação, habilidades ou outros recursos; (iv) instrumentos de exortação e simbólicos manipulam símbolos e valores, entendendo que as pessoas estão mais dispostas a agir de acordo com políticas que são consistentes com suas crenças; e, por fim, ( $v)$ instrumentos de aprendizado promovem o conhecimento e a construção de consenso, assumindo que as pessoas podem não saber o que deve ou pode ser feito. 
Diante de tantas possibilidades, outro tema que ganha relevo é o da seleção dos instrumentos. Capano e Lippi (2017) sustentam que essa escolha se caracteriza pela influência recíproca entre as preferências dos decisores (percepções, ideologias, entre outras) e os constrangimentos contextuais (perfil institucional, opinião pública, grupos de atenção, entre outros). Como resultante, ter-se-iam duas lógicas: a consequencial, orientada pelo princípio da instrumentalidade, valorizando instrumentos que favorecem o cumprimento dos objetivos; e a lógica da adequação, direcionada pelo princípio da legitimidade, prezando a seleção de instrumentos mais ajustados aos valores sociais. Combinando os princípios de instrumentalidade e de legitimidade, os autores demarcam quatro padrões de adoção de instrumentos: (i) rotinização: escolha constrangida pela rotina, com a adoção de instrumentos conhecidos e manuseados; (ii) contaminação: adoção influenciada pelo contexto político do subsistema, com vistas a criar consenso diante de algum distúrbio nas relações e/ou percepções de inefetividade da política; (iii) hibridização: padrão de decisão em que os decisores são forçados a inserir um novo instrumento especializado pela necessidade de manter e/ou gerar legitimidade externa, havendo esforço de ajustamento com os instrumentos pré-existentes; (iv) estratificação: introdução de instrumentos de forma genérica em virtude de sua natureza atraente, também visando a legitimidade externa; o que difere do anterior é a ausência de esforço de congruência com os instrumentos existentes.

De outro ângulo, Linder e Peters (1989) atentam para as preferências por instrumentos que decorrem dos contextos políticos e organizacionais, especificamente: $(i)$ contexto sistêmico: os estilos políticos nacionais influenciariam as preferências por determinados tipos de instrumentos: tradições estatistas aceitariam instrumentos que manuseiam maiores níveis de coerção; onde as clivagens sociais são acentuadas, haveria preferência por instrumentos menos intrusivos; já nas sociedades mais pluralistas, preferir-se-iam instrumentos de transferência de informação; (ii) contexto organizacional: organizações exibem preferências por instrumentos a depender do perfil de sua clientela, das ideias hegemônicas no momento de sua criação, dos propósitos institucionais, das características da comunidade de política prevalecente, da socialização profissional das e dos trabalhadores recrutados e dos grupos profissionais dominantes. 
Agregando-se ao debate da escolha entre instrumentos, um conceito interessante proposto para explicar a inovação e a mudança é o de instrument constituency: redes de atores reunidos em torno de alternativas específicas e práticas relacionadas, que agem de forma a difundi-las e implantá-las (VOSS; SIMONS, 2014). Desse modo, essas redes se diferenciam daquelas que compartilham uma definição de problema, como as comunidades epistêmicas, ou a promoção de agendas políticas, como as coalisões de defesa, atuando na promoção de instrumentos particulares (BÉLAND; HOWLETT, 2016). Assim, são consideradas um novo tipo de comunidade nessa constelação, constituindo mais uma evidência para o argumento de que soluções buscam problemas, nos termos de Kingdon (1995).

Enfim, essa literatura oferece diversas formas de abordar os instrumentos, cobrindo uma ampla gama de questões. Não é de surpreender que problemas e objetivos sejam tomados como dados, de construção exógena à seleção dos instrumentos. Em contraste, uma grande atenção é dispensada para a relação com o comportamento e conformidade dos beneficiários. O que nos conduz ao próximo tópico.

Beneficiários: imagem social e recursos de poder

Como vimos, quando os estudos sobre instrumentos abordam o público-alvo das políticas, eles costumam enfatizar de que forma o desenho pode influenciar seu comportamento. Uma visão diferente advém dos trabalhos de Anne Schneider e Helen Ingram, que desenvolveram a abordagem da construção social das populações-alvo, a segunda linha mais prolífica no campo do policy design ao lado dos estudos sobre instrumentos.

Nessa abordagem, os grupos afetados pela política são vistos a partir das racionalidades e das justificações subjacentes aos desenhos, que expressariam ideias veladas acerca de suas credenciais como merecedores e não merecedores, confiáveis e não confiáveis. Tais construções informariam a escolha de instrumentos condizentes, que alocariam benefícios aos grupos positivamente construídos e fardos aos estigmatizados como dependentes e desviantes, gerando efeitos sociais e políticos deletérios (SCHNEIDER; INGRAM, 1988).

Aqui, o público-alvo corresponde a pessoas, grupos e organizações impactados pela política (SCHNEIDER, 2015). Na perspectiva da construção 
social, assume-se que os policy-makers constroem socialmente as populações-alvo em termos positivos e negativos e distribuem benefícios e fardos que refletem e perpetuam essas construções (INGRAM; SCHNEIDER; DELEON, 2007). Isso seria uma consequência das heurísticas decisórias e de vieses cognitivos inseridos no processo de desenho (SCHNEIDER, 2015). Por decorrência, os desenhos contêm construções sociais, imagens e símbolos que enviam mensagens à população-alvo e ao público mais geral sobre quem merece o quê e por quê (SCHNEIDER, 2015).

Para operacionalizar analiticamente essa ideia, Ingram, Schneider e Deleon (2007) e Schneider (2015) formularam uma tipologia de grupos beneficiários elaborada a partir da intersecção de dois critérios, poder político e imagem social, positiva (merecedores) ou negativa (não merecedores) - (i) favorecidos: politicamente poderosos e positivamente construídos como merecedores, inteligentes e trabalhadores; (ii) contenders: politicamente poderosos, mas com imagem negativa de gananciosos e desonestos; (iii) dependentes: politicamente fracos, mas com imagem positiva de pessoas boas por serem necessitados; (iv) desviantes: politicamente fracos e com imagem negativa de perigosos, violentos, maus e egoístas.

Segundo as autoras, os desenhos das políticas alocarão valores, benefícios e fardos, de forma diferente a depender do grupo em questão. Aos grupos favorecidos e aos dependentes alocam-se benefícios com características distintas: regras universais, estruturas de implementação coordenadas e fraco monitoramento para o primeiro; regras particularistas, serviços despersonalizados com grande discrição para os operadores, numerosas regras de disciplina e testes de meios para o segundo. Aos desviantes, punições e disciplina; e aos contenders, benefícios encobertos por intricamento jurídico, juntamente com fardos, como discursos e narrativas negativas.

A abordagem reconhece que o desenho tem consequências sociais e políticas fundamentais não somente no bem-estar material, mas na reputação social e em como os segmentos da população veem seu relacionamento com o governo e com o Estado (INGRAM; SCHNEIDER; DELEON, 2007; SCHNEIDER, 2015). Explicando: quando o desenho constrói o beneficiário negativamente, geralmente há reforço da exclusão, da marginalização, desestímulo à participação política e atitudes negativas em relação ao Estado. De 
outra forma, o tratamento positivo promove a autoconfiança e o sentimento de pertença social, incentivando o interesse e a participação.

Como aponta Schneider (2015), os desenhos com mais apoio e mais facilmente difundidos são aqueles que provêm benefícios aos favorecidos. Tal dinâmica é denominada degenerative policy: a prática sustentada de prover benefícios aos grupos favorecidos e fardos aos desfavorecidos perpetua e agrava as divisões sociais, prejudicando a percepção de justiça e afetando negativamente o escopo da democracia (SCHNEIDER; INGRAM, 1990).

Como se vê, o debate sobre os grupos afetados pela política é mais desenvolvido no trabalho dessas autoras que defendem uma abordagem normativa, enfocando o impacto dos desenhos sobre a democracia. Com isso, o desenho emerge, também, como variável independente, no sentido que produz múltiplas consequências para a sociedade. Desponta, então, uma visão de resultado de política distinta daquelas que veremos a seguir.

\section{Resultados: definindo sucesso e fracasso}

O último elemento do desenho a ser examinado são os resultados. Nesse recorte, uma questão que ganha atenção é o da ambiguidade que acompanha as definições de sucesso e de fracasso. Para Howlett (2012), muitas vezes essas categorias são vistas como julgamentos subjetivos ou declarações de interesses que não recebem qualquer status de objetividade, impossibilitando esclarecimento e compartilhamento.

Tentando lidar com isso, Compton, Luetjens e Hart (2019) alegam que sucesso e fracasso são construídos como histórias, moldadas por eventos percebidos como indubitáveis, mas de importância incerta e/ou controversa. Assim, rotular algo como um "sucesso" é um ato de interpretação, informado por avaliações positivas de organizações profissionais como think tanks, agências governamentais, auditorias, entre outras. Tais avaliações funcionam como um voto de confiança a atos e práticas, elevando-os e validando-os. Já o rótulo de "fracasso" vem envolto em feedback negativo, colocando em movimento uma série de rituais organizacionais de prestação de contas, alocação de culpa e aprendizado, de forma a demonstrar que não haverá repetição.

Com essas preocupações, a literatura se volta ao estabelecimento de dimensões e parâmetros para definir sucesso e fracasso. Em Linder e Peters 
(1990), por exemplo, encontramos uma proposição básica: determinar a partir dos objetivos acordados ou do resultado do processo de negociação entre organizações diversas, enfatizando a legitimidade. Também Howlett (2012) elenca alguns conceitos que tentam diferenciar com mais rigor entre tipos de fracassos, conforme Quadro 1.

Quadro 1 - Designações para fracasso

\begin{tabular}{|llll|}
\hline & & $\begin{array}{c}\text { Teoria e evidência usadas para } \\
\text { formular programas e planos }\end{array}$ \\
\cline { 3 - 4 } & Eficientemente executada ou melhores práticas & Anomalias de políticas & Erros de políticas \\
\hline $\begin{array}{c}\text { Execução de } \\
\text { política }\end{array}$ & Ineficientes ou mal executadas & Acidentes de políticas & Fiascos de políticas \\
\hline
\end{tabular}

Fonte: Howlett, 2012, p. 551, tradução nossa.

Um trabalho recente, e que tem recebido atenção, é o de Compton, Luetjens e Hart (2019), o qual propõe uma forma de avaliar sucesso a partir de quatro dimensões: (i) programática: considerando a consecução dos objetivos; (ii) processual: com foco na organização e gerenciamento dos processos de decisão, examinando sua abertura para as evidências, argumentos e persuasão; (iii) política: atenção ao grau com que formuladores e implementadores podem criar e manter apoio político; (iv) resistência: foco na robustez das políticas diante das mudanças contextuais, em termos de aprendizagem e flexibilidade, manutenção de suporte político, reputação e legitimidade. Embasados nessas dimensões, os autores defendem que uma política é bem-sucedida quando "cria propositalmente resultados sociais amplamente valorizados por meio de processos rigorosos, e consegue sustentar esse desempenho por um longo período de tempo, mesmo em face de circunstâncias mutantes" (COMPTON; LUETJENS; HART, 2019, p. 123, tradução nossa).

Com isso, o campo oferece uma delimitação para os resultados, a qual aparece bastante alinhada ao conceito de desenho, conforme estudado aqui. Ademais, nessas definições percebe-se o entrelaçamento de diversas dimensões: organizacional, da atividade política, das preferências expressas nos desenhos - o que salienta a instrumentalidade e a legitimidade, ou seja, ideias que perpassaram, igualmente, as discussões sobre os demais elementos. 


\section{Desenho de políticas públicas no Brasil: delineando uma agenda de pesquisa}

A partir da metodologia empregada, não surgiram artigos nacionais no corpus de pesquisa. Assim, procedemos a uma busca no Google Acadêmico, em novembro de 2020, utilizando as palavras-chave "instrumentos de políticas públicas" e "desenho de políticas públicas", a fim de incorporar estudos nacionais.

Com esse movimento, encontramos três trabalhos - todos enfocando os instrumentos de implementação. Amorim e Boullosa (2013) debatem sobre as abordagens funcionalista e sociopolítica de instrumentos. As autoras mobilizam o conceito de Lascoumes e Le Galès (2007, 2012), que ressalta a plasticidade dos instrumentos, tendo em vista as demandas políticas de atores envolvidos. Desse modo, as autoras tratam da dimensão política dos instrumentos, afirmando ser esse o critério preponderante de escolha em detrimento das questões técnicas. Já Lucio, Daroit e Freitas (2017) realizaram pesquisa empírica, analisando os instrumentos do Programa Bolsa Família (PBF) desde uma abordagem de transversalidade. Também aqui, o conceito orientador é o de Lascoumes e Le Galès (2012), por meio do qual as autoras investigam o caráter político, os usos e resultados dos instrumentos de gestão do PBF.

O debate trazido pelas autoras citadas está bastante focado no questionamento da tecnicidade dos instrumentos, frisando que: "ao contrário do que é comumente afirmado, a escolha do instrumento de políticas públicas não seria uma questão técnica, mas política" (AMORIM; BOULLOSA, 2013, p. 64). Com isso, os instrumentos refletiriam e operacionalizariam escolhas estratégicas e projetos políticos, "constituindo-se em espaços de ação pública" (LUCIO; DAROIT; FREITAS, 2017, p. 300). Ambos os artigos não mencionam alinhamento à literatura de policy design, o foco é bem específico nos instrumentos e na operacionalização do conceito de Lascoumes e Le Galès. Em relação ao conjunto de trabalhos discutidos nas seções anteriores, o conceito de Lascoumes e Le Galès (2012) é citado apenas em Vargas e Restrepo (2019), dentre diversos outros utilizados para realizar uma revisão da literatura sobre instrumentos. Tais evidências indicam que os trabalhos nacionais estudados não se mostram posicionados na literatura sobre policy design.

O terceiro artigo é o de Ollaik e Medeiros (2011). Nele, as autoras oferecem uma sistematização de fôlego da literatura sobre instrumentos, 
enfatizando os conceitos e, especialmente, as tipologias. O artigo se dedica a discutir os instrumentos no contexto da implementação de políticas públicas. Assim como os outros, esse trabalho não indica enquadramento na literatura sobre policy design, mas cita alguns autores relevantes desta. Ao final, as autoras concluem que são necessários mais estudos no Brasil e sugerem quatro linhas para uma agenda de pesquisa: (i) estudos sobre processos de escolhas de instrumentos; (ii) sistematização de tipologias dos instrumentos manuseados pelos governos, criando uma classificação brasileira; (iii) como ocorre o processo de implementação das políticas tendo em vista os instrumentos utilizados; e (iv) comparação entre instrumentos, para verificar sua aplicação e diferentes impactos.

Como se viu, dez anos depois, essa agenda ainda está por ser desenvolvida. Somando-nos, reforçando e ampliando esse esforço, considerando a literatura sobre policy design mapeada, tecemos algumas sugestões para uma agenda de pesquisa.

Um primeiro ponto que merece atenção diz respeito a algumas características da federação brasileira. A concentração de recursos técnicos e financeiros na União faz com que as políticas sejam tradicionalmente elaboradas em âmbito central e adaptadas aos contextos locais. Assim, torna-se relevante observar como estados e municípios endogenizam desenhos, promovem mudanças nos elementos previamente definidos e quais são os resultados. Por outro lado, estados e municípios gozam de autonomia política e administrativa e formulam políticas públicas locais. Nesse contexto, torna-se relevante investigar a congruência dos desenhos, considerando-se os objetivos específicos, o conjunto disponível de instrumentos, as limitações orçamentárias e as relações intergovernamentais. Também cabe verificar processos de difusão de elementos de desenho entre estados, entre municípios e entre estados e municípios.

Um segundo ponto tange à influência de programas globais, como a Agenda 2030. Tais acordos oportunizam estudos sobre quais desenhos vêm sendo valorizados para dar conta dos complexos problemas sociais contemporâneos. Como os governos modelam problemas e objetivos para atender essas agendas? Quais os instrumentos mais acionados? Abrindo espaço para a comparação entre políticas de diferentes governos assim como para a análise de congruência da estrutura lógicas destas iniciativas. 
Já o terceiro ponto se refere à perspectiva de criação de instituições voltadas a desenhar políticas públicas, a exemplo dos laboratórios de inovação, que podem ser definidos como "unidades governamentais multidisciplinares que usam uma variedade de métodos de inovação, incluindo design, para envolver de forma colaborativa os usuários e as partes interessadas no serviço e no desenvolvimento de políticas" (WHICHER, 2021, p. 4, traduação nossa). A partir do ano de 2010, houve um espraiamento desse tipo de iniciativa no mundo como forma de buscar maior aproximação, interação e participação da sociedade para além dos padrões verificados até então no setor público, com vistas a dar respostas governamentais mais eficientes a problemas sociais complexos (SANO, 2020). Nesse sentido, seria interessante compreender se e de que forma os laboratórios de inovação no setor público contribuem para a melhoria do desenho de políticas públicas no Brasil. Quais ferramentas/técnicas/metodologias são aplicadas para desenhar colaborativamente as políticas públicas? Como os laboratórios ajudam na endogenização das políticas a nível local considerando o contexto federativo brasileiro?

A quarta consideração diz respeito à forma como o Poder Executivo vem se relacionando com os órgãos de controle do Brasil (seja TCU, o TCE, ou comitês participativos e afins). Ou seja, os critérios e as formas de controle geram expectativas e operam conduzindo atenção e esforços em direção a dados elementos do desenho ou mesmo valorizando certo tipo de estrutura lógica. Nessa linha, também podem ser analisadas as preferências das organizações em relação a dadas configurações de desenhos e instrumentos.

Por fim, é preciso apontar que, dada a multiplicidade de áreas de políticas e heterogeneidades coexistentes no Brasil, pode-se ter desenhos mais dados à centralização do governo central, outros mais abertos às formas de participação social e governança, outros com maior previsão de engajamento dos entes subnacionais etc. Essas características devem ser observadas na forma como futuras pesquisas serão orientadas.

\section{Considerações finais}

O propósito deste artigo foi explorar a literatura sobre policy design e delinear uma agenda de pesquisa. Nesse caminho, realizamos um mapeamento dessa subárea da policy analysis, identificando conceitos e abordagens. 
Verificamos que o conceito de desenho traz três ideias-força: (i) de que o desenho é formado por diversos elementos, que fornecem estrutura e informam a dinâmica das políticas; (ii) que esses elementos devem exibir conexão lógica; (iii) e que a análise e a produção de conhecimento sobre a estrutura e a dinâmica dos desenhos está comprometida com o incremento da qualidade das políticas públicas. Em um primeiro olhar, isso sugere um caráter técnico e, aparentemente, apolítico à perspectiva. Contudo, tal imagem se desfaz à medida que nos aprofundamos nos debates que se desenrolam em torno de cada um dos elementos formadores dos desenhos.

Nessa perspectiva, percebemos que a ideia de conexão não demanda sequencialidade, mas está envolta em dinâmicas contingentes, fortemente relacionada à movimentação das e dos atores, aos conflitos entre interesses e ideias, abrangendo, aí, as potencialidades e os constrangimentos de natureza institucional e organizacional. Esse fundamento favorece a expansão dos estudos dedicados a cada elemento. Paradoxalmente, tal especialização desvia a atenção da temática da relação entre eles, que aparece com centralidade nos conceitos, mas não recebe tratamento analítico ou é tomada como dada. Isso oportuniza pesquisas sobre congruência entre elementos de desenhos. Além disso, pesquisas sobre transferência e difusão de desenhos, bem como sobre preferências organizacionais, permitem expandir esse ponto.

De forma geral, este trabalho apresenta duas principais contribuições: a primeira delas é de ordem metodológica. As revisões narrativas são artigos educacionais úteis, pois reúnem muitas informações em um formato inteligível (GREEN; JOHNSON; ADAMS, 2006). Nesse sentido, apresentam uma perspectiva ampla sobre um tópico, que, além de discutir teoria e contexto, podem servir para provocar reflexão e controvérsia (SLAVIN, 1995). A segunda contribuição está na síntese de um campo fragmentado, recente e efervescente de pesquisa. Este artigo revisa essa literatura e fornece uma visão geral, um mapa conceitual do campo de policy design. Esse esforço permitiu identificar temas centrais e periféricos, assim como forneceu uma base para uma agenda futura de pesquisa.

Por fim, as constatações feitas neste estudo devem ser compreendidas à luz de algumas limitações. Em relação ao conteúdo, ao longo das explanações é possível identificar pontos que podem ser enriquecidos e mais bem 
desenvolvidos acionando outros campos da policy analysis, o que se explicita no caso da discussão sobre os resultados, que se beneficiaria de uma aproximação com a literatura sobre avaliação. Quanto ao procedimento metodológico: (i) as revisões narrativas são normalmente escritas por especialistas em determinada área de pesquisa, fornecendo, assim, perspectivas intuitivas e experienciais em tópicos bem focalizados (MANCHIKANTI et al., 2009); e (ii) a ausência de critérios de seleção objetivos e sistemáticos no método de revisão resulta em viés de interpretação e de conclusões (PAE, 2015). No que diz respeito à amostragem, a técnica em bola de neve não é aleatória, consequentemente, a amostra não deve ser considerada representativa da população (BIERNACKI; WALDORF, 1981). E quanto à seleção dos documentos, a utilização de artigos disponíveis de forma on-line e gratuita, ou de livros e capítulos de livros que puderam ser adquiridos, pode ter deixado de fora importantes estudos.

\section{Referências}

ACCIAI, Claudia; CAPANO, Giliberto. Climbing down the ladder: a meta-analysis of policy instruments applications. In: IPPA INTERNATIONAL WORKSHOPS ON PUBLIC POLICY, University of Pittsburgh, 26-28 jun. 2018, Pittsburgh. Papers [...]. Pittsburgh: IPPA, 2018. p. 1-32.

AL-KOHLANI, Sumaia A.; CAMPBELL, Heather E. Rank-order implications of social construction theory: does air quality depend on social constructions? Policy Sciences, Dordrecht, v. 49, n. 4, p. 467-488, 14 dez. 2016.

AMORIM, Simone; BOULLOSA, Rosana de Freitas. O estudo dos instrumentos de políticas públicas: uma agenda em aberto para experiências de migração de escala. Amazônia, Organizações e Sustentabilidade, Belém, v. 2, n. 1, p. 59-69, 2013.

BALDIN, Nelma MUNHOZ, Elzira M. Bagatin. Educação ambiental comunitária: uma experiência com a técnica de pesquisa snowball (bola de neve). REMEA - Revista Eletrônica do Mestrado em Educação Ambiental, Rio Grande, v. 27, p. 46-60, 2011.

BARDACH, Eugene. On designing implementable programs. In: MAJONE, Giandomenico; QUADE, Edward S. (ed.). Pitfalls of analysis. New York: John Wiley \& Sons, 1980. p. 138-158. 
BAUMEISTER, Roy F.; LEARY, Mark R. Writing narrative literature reviews. Review of General Psychology, Washington, D.C., v. 1, n. 3, p. 311-320, $1^{\circ}$ set. 1997.

BÉLAND, Daniel; HOWLETT, Michael. How solutions chase problems: instrument constituencies in the policy process. Governance, Oxford, v. 29, n. 3, p. 393-409, 2016.

BIERNACKI, Patrick; WALDORF, Dan. Snowball sampling: problem and of using nonrandom sampling methodologies. Sociological Methods \& Research, Thousand Oaks, v. 10, p. 141-163, 1981.

BRASIL, Felipe G.; CAPELLA, Ana Claudia N. Os estudos das políticas públicas no Brasil: passado, presente e caminhos futuros da pesquisa sobre análise de políticas. Revista Política Hoje, Recife, v. 25, n. 1, p. 71-90, 2016.

BURNARD, Philip. A method of analysing interview transcripts in qualitative research. Nurse Education Today, [Online], v. 11, n. 6, p. 461-466, dez. 1991. CAPANO, Giliberto; HOWLETT, Michael. Causal logics and mechanisms in policy design: how and why adopting a mechanistic perspective can improve policy design. Public Policy and Administration, London, v. 36, n. 2, p. 1-22, 2021.

CAPANO, Giliberto; HOWLETT, Michael. The knowns and unknowns of policy instrument analysis: policy tools and the current research agenda on policy mixes. SAGE Open, [Online], v. 10, n. 1, p. 1-13, 2020.

CAPANO, Giliberto; LIPPI, Andrea. How policy instruments are chosen: patterns of decision makers' choices. Policy Sciences, Dordrecht, v. 50, n. 2 , p. 269-293, 2017.

CHINDARKAR, Namrata; HOWLETT, Michael; RAMESH, M. Introduction to the special issue:"conceptualizing effective social policy design: design spaces and capacity challenges". Public Administration and Development, Chichester, v. 37, n. 1, p. 3-14, 2017.

COLEBATCH, Hal K. The idea of policy design: intention, process, outcome, meaning and validity. Public Policy and Administration, London, v. 33, n. 4, p. 365-383, 2018.

COMPTON, Mallory E.; LUETJENS, Joannah; HART, Paul. Designing for policy success. International Review of Public Policy, [Online], v. 1, n. 2, p. 119-146, 2019. 
CONSIDINE, Mark. Thinking outside the box? Appying design theory to public policy. In: HOWLETT, Michael; MUKHERJEE, Ishani (ed.). Routledge Handbook of Policy Design. New York: Routledge, 2018. p. 147-160.

DE VRIES, Michiel S.; NEMEC, Juraj; JUNJAN, Veronica. The choice-arquitecture behind policy designs: an introduction to this volume. In: DE VRIES, Michiel; NEMEC, Juraj; JUNJAN, Veronica (ed.). The choice-architecture behind policy design: from policy design to policy practice in the European integration context. Bratislava: NISPAcee, 2020. p. 11-19.

DELEON, Peter. The historical roots of the field. In: MORAN, Michael; REIN, Martin; GOODIN, Robert E. (ed.). The Oxford Handbook of Public Policy. Oxford: Oxford University Press, 2008. p. 39-57.

DEY, Ian. Qualitative data analysis: a user friendly guide for social scientists. London: Routledge and Kegan Paul, 1993.

DOWNE-WAMBOLDT, B. Content analysis: method, applications, and issues. Health Care for Women International, Philadelphia, v. 13, n. 3, p. 313-321, jan. 1992.

DRYZEK, John S.; RIPLEY, Brian. The ambitions of policy design. Policy Studies Review, [Online], v. 7, n. 4, p. 705-719, 1988.

ELIADIS, Pearl; HILL, Margaret M.; HOWLETT, Michael (ed.). Designing government: from instruments to governance. Québec: McGill-Queen's University Press, 2005.

ELO, Satu; KYNGÄS, Helvi. The qualitative content analysis process. Journal of Advanced Nursing, Oxford, v. 62, n. 1, p. 107-115, abr. 2008.

GOMES, Sandra. Sobre a viabilidade de uma agenda de pesquisa coletiva integrando implementação de políticas, formulação e resultados. In: LOTTA, Gabriela (ed.). Teorias e análises sobre implementação de políticas públicas no Brasil. Brasília: Enap, 2019. p. 39-64.

GREEN, Bart N.; JOHNSON, Claire D.; ADAMS, Alan. Writing narrative literature reviews for peer-reviewed journals: secrets of the trade. Journal of Chiropractic Medicine, [Online], v. 5, n. 3, p. 101-117, set. 2006.

GREENHALGH, Trisha; PEACOCK, Richard. Effectiveness and efficiency of search methods in systematic reviews of complex evidence: audit of primary sources. BMJ, [Online], v. 331, n. 7524, p. 1064-1065, 5 nov. 2005. 
HERMUS, Margot; VAN BUUREN, Arwin; BEKKERS, Victor. Applying design in public administration: a literature review to explore the state of the art. Policy \& Politics, [Online], v. 48, n. 1, p. 21-48, 2020.

HILGARTNER, Stephen; BOSK, Charles L. The rise and fall of social problems: a public arenas model. American Journal of Sociology, Chicago, v. 94, n. 1, p. 53-78, 1988.

HOOD, Christopher C. The tools of government. 1. ed. London: The Macmillan Press, 1983.

HOPPE, Robert. Rules-of-thumb for problem-structuring policy design. Policy Design and Practice, [Online], v. 1, n. 1, p. 12-29, 2018.

HOWLETT, Michael. Aligning policy tools and their targets: nudging and utility maximization in policy design. In: HOWLETT, Michael; MUKHERJEE, Ishani (ed.). Routledge Handbook of Policy Design. New York: Routledge, 2018a. p. 106-121. HOWLETT, Michael. Challenges in applying design thinking to public policy: dealing with the varieties of policy formulation and their vicissitudes. Policy \& Politics, [Online], v. 48, n. 1, 9 set. 2019.

HOWLETT, Michael. Challenges in applying design thinking to public policy: dealing with the varieties of policy formulation and their vicissitudes. Policy \& Politics, [Online], v. 48, n. 1, p. 49-65, $1^{\circ}$ jan. 2020.

HOWLETT, Michael. Designing public policies. New York: Routledge, $2011 \mathrm{a}$. HOWLETT, Michael. Policy instruments and policy design choices: selecting substantive and procedural tools in public policymaking. In: HOWLETT, Michael; MUKHERJEE, Ishani (ed.). Routledge Handbook of Policy Design. New York: Routledge, 2018b. p. 77-86.

HOWLETT, Michael. Revisiting policy design: the rise and fall (and rebirth?) of policy design studies. In: GENERAL CONFERENCE OF THE EUROPEAN CONSORTIUM FOR POLITICAL RESEARCH (ECPR), 26 ago. 2011, Reykjavik. Papers [...]. Reykjavik: ECPR, 2011b. p. 1-32. Section 63.

HOWLETT, Michael. The lessons of failure: learning and blame avoidance in public policy-making. International Political Science Review, London, v. 33, n. 5, p. 539-555, 2012.

HOWLETT, Michael; LEJANO, Raul P. Tales from the crypt: the rise and fall (and rebirth?) of policy design. Administration \& Society, Thousand Oaks, v. 45, n. 3 , p. 357-381, 2012. 
HOWLETT, Michael; MUKHERJEE, Ishani. The importance of policy design: effective processes, tools and outcomes. In: HOWLETT, Michael; MUKHERJEE, Ishani (ed.). Routledge Handbook of Policy Design. New York: Routledge, 2018. p. 3-19.

HOWLETT, Michael; MUKHERJEE, Ishani; RAYNER, Jeremy. Understanding policy designs over time: layering, stretching, patching and packaging. In: HOWLETT, Michael; MUKHERJEE, Ishani (eds.). Routledge Handbook of Policy Design. New York: Routledge, 2018. p. 136-144.

HOWLETT, Michael; MUKHERJEE, Ishani; WOO, Jun Jie. From tools to toolkits in policy design studies: the new design orientation towards policy formulation research. Policy \& Politics, [Online], v. 43, n. 2, p. 291311, 30 abr. 2015.

INGRAM, Helen; SCHNEIDER, Anne L. Policy analysis for democracy. In: MORAN, Michael; REIN, Martin; GOODIN, Robert E. (ed.). The Oxford Handbook of Public Policy. Oxford: Oxford University Press, 2008. p. 169-189.

INGRAM, Helen; SCHNEIDER, Anne L.; DELEON, Peter. Social construction and policy design. In: SABATIER, Paul A. (ed.). Theories of the policy process. 2. ed. Boulder: Westview Press, 2007. p. 93-126.

JANNUZZI, Paulo de Martino. Eficiência econômica, eficácia procedural ou efetividade social: três valores em disputa na avaliação de políticas e programas sociais. Desenvolvimento em Debate, [Online], v. 4, n. 1, p. 117$142,2016$.

JUNJAN, Veronica. Policy design: just a fad or a fundamental concept? (Or how to deal with policy design in interesting times). In: DE VRIES, Michiel S.; NEMEC, Juraj; JUNJAN, Veronica (ed.). The choice-architecture behind policy design: from policy design to policy practice in the European integration context. Bratislava: NISPAcee, 2020. p. 21-31.

KERN, Florian; ROGGE, Karoline S.; HOWLETT, Michael. Policy mixes for sustainability transitions: new approaches and insights through bridging innovation and policy studies. Research Policy, [Online], v. 48, n. 10, 103832, 2019.

KINGDON, John. W. Agendas, alternatives, and public policies. 2. ed. New York: HarperCollins College Publishers, 1995. 
KUEHNHANSS, Colin R. Nudges and nodality tools: new developments in old instruments. In: HOWLETT, Michael; MUKHERJEE, Ishani (ed.). Routledge Handbook of Policy Design. New York: Routledge, 2018. p. 227-242.

LASCOUMES, Pierre; LE GALÈS, Patrick. Introduction: understanding public policy through its instruments-from the nature of instruments to the sociology of public policy instrumentation. Governance, Oxford, v. 20, n. 1, p. 1-21, 2007.

LASCOUMES, Pierre; LE GALÈS, Patrick. Sociologia da ação pública. Maceió: EDUFAL, 2012.

LAURI, S.; KYNGÄS, H. Developing nursing theories. Vantaa, Finland: Werner Söderström; Dark Oy, 2005.

LEVIN, K. et al. Overcoming the tragedy of super wicked problems: constraining our future selves to ameliorate global climate change. Policy Sciences, Dordrecht, v. 45, n. 2, p. 123-152, 2012.

LINDBLOM, Charles E. The science of "muddling through". Public Administration Review, [Online], v. 19, n. 2, p. 79-88, 1959.

LINDER, Stephen H.; PETERS, B. Guy. Instruments of government: perceptions and contexts. Journal of Public Policy, Cambridge, v. 9, n. 1, p. 35-58, 1989.

LINDER, Stephen H.; PETERS, B. Guy. Research perspectives on the design of public policy: implementation, formulation, and design. In: PALUMBO, Dennis J.; CALISTA, Donald J. (ed.). Implementation and the policy process: opening up the black box. Westport: Greenwood Press, 1990. p. 51-66. LINDER, Stephen H.; PETERS, B. Guy. The analysis of design or the design of analysis? Review of Policy Research, Malden, v. 7, n. 4, p. 738-750, jun. 1988. LIPSKY, Michael. Street-level bureaucracy: dilemmas of the individual in public services. New York: Russel Sage Foundation, 2010.

LOWI, Theodore J. American business, public policy, case studies, and political theory. World Politics, Baltimore, v. 16, n. 4, p. 677-715, 1964.

LUCIO, Magda de Lima; DAROIT, Doriana; FREITAS, Urânia Flores da Cruz. Desenvolvimento, ação pública e transversalidade dos instrumentos de gestão: um olhar sobre o programa Bolsa Família. In: LIMA, Luciana Leite; RODRIGUES, Maria Isabel (ed.). Campo de pública em ação: coletânea em teoria e gestão de políticas públicas. Porto Alegre: UFRGS/CEGOV, 2017. p. 292-313. 
MANCHIKANTI, Laxmaiah et al. Evidence-based medicine, systematic reviews, and guidelines in interventional pain management: part 3: systematic reviews and meta-analyses of randomized trials. Pain Physician, [Online], v. 12, n. 1, p. 35-72, 2009.

McGANN, Michael; WELLS, Tamas; BLOMKAMP, Emma. Innovation labs and co-production in public problem solving. Public Management Review, London, v. 23, n. 2, p. 297-316, 2021.

MULLER, Pierre; SUREL, Yves. A análise das políticas públicas. Pelotas: EDUCAT, 2002.

NEWMAN, Joshua; NURFAIZA, Martha W. Policy design, non-design, and anti-design: the regulation of e-cigarettes in Indonesia. Policy Studies, Abingdon, p. 1-18, 2020.

OLLAIK, Leila G.; MEDEIROS, Janann J. Instrumentos governamentais: reflexões para uma agenda de pesquisas sobre implementação de políticas públicas no Brasil. Revista de Administração Pública, Rio de Janeiro, v. 45, n. 6, p. 1943-1967, 2011.

OSTROM, Elinor. Understanding institutional diversity. Princeton: Princeton University Press, 2005.

PAE, Chin-Un. Why systematic review rather than narrative review? Psychiatry Investigation, [Online], v. 12, n. 3, p. 417-419, 2015.

PETERS, B. Guy. Advanced introduction to public policy. Massachusetts: Edward Elgar, 2015.

PETERS, B. Guy. Designing institutions for designing policy. Policy \& Politics, [Online], v. 48, n. 1, p. 131-147, 2020a.

PETERS, B. Guy. Policy design and its relevance for practice in public administration. In: DE VRIES, Michiel S.; NEMEC, Juraj; JUNJAN, Veronica (ed.). The choice-architecture behind policy design: from policy design to policy practice in the European integration context. Bratislava: NISPAcee, 2020b. p. 35-46.

PETERS, B. Guy; NAGEL, Maximilian. Zombie ideas: Why Failed Policy Ideas Persist (Elements in Public Policy). Cambridge: Cambridge University Press, 2020. PETERS, B. Guy; RAVA, Nenad. Policy design: from technocracy to complexity, and beyond. In: IPPA INTERNATIONAL PUBLIC POLICY CONFERENCE, 28-30 jun. 2017, Singapore. Papers [...]. Singapore: IPPA, 2017. p. 1-23. 
PETERS, B. Guy; VAN NISPEN, Frans K. (ed.). Public policy instruments: evaluating the tools of public administration. Cheltenham: Edward Elgar, 1998.

PLUCHINOTTA, Irene et al. Integrating problem structuring methods and concept-knowledge theory for an advanced policy design: lessons from a case study in Cyprus. Journal of Comparative Policy Analysis: Research and Practice, [Online], v. 22, n. 6, p. 626-647, $1^{\circ}$ nov. 2020.

RITTEL, Horst W. J.; WEBBER, Melvin M. Dilemmas in a general theory of planning. Policy Sciences, Dordrecht, v. 4, n. 2, p. 155-169, 1973.

ROBSON, Colin. Real world research: a resource for social scientists and practitioner-researchers. [S. l.]: Blackwell Oxford, 2002. v. 2.

ROGGE, Karoline S. Designing complex policy mixes. In: HOWLETT, Michael; MUKHERJEE, Ishani (ed.). Routledge Handbook of Policy Design. New York: Routledge, 2018. p. 34-58.

SABATIER, Paul A.; MAZMANIAN, Daniel. The implementation of public policy: a framework of analysis. Policy Studies Journal, Malden, v. 8, n. 4, p. 538-560, 1980.

SABATIER, Paul A. (ed.). Theories of the policy process. Colorado: Westview Press, 2007.

SALAMON, Lester M. (ed.). The tools of government: a guide to the new governance. Oxford: Oxford University Press, 2002a.

SALAMON, Lester. M. The new governance and the tools of public action: an introduction. In: SALAMON, Lester M. (ed.). The tools of government: a guide to the new governance. Oxford: Oxford University Press, 2002b. p. 1-47.

SANDERSON, Ian. Evaluation, policy learning and evidence-based policy making. Public Administration, Oxford, v. 80, n. 1, p. 1-22, 2002.

SANO, Hironobu. Laboratórios de inovação no setor público: mapeamento e diagnóstico de experiências nacionais. Brasília: Enap, 2020.

SCHNEIDER, Anne. Policy design and transfer. In: ARARAL, Eduardo et al . (ed.). Routledge Handbook of Public Policy. Abinddon: Routledge, 2015. p. 217-228.

SCHNEIDER, Anne; INGRAM, Helen. Behavioral assumptions of policy tools. The Journal of Politics, Malden, v. 52, n. 2, p. 510-529, 1990. 
SCHNEIDER, Anne; INGRAM, Helen. Systematically pinching ideas: a comparative approach to policy design. Journal of Public Policy, Cambridge, v. 8, n. 1, p. 61-80, 1988.

SCHNEIDER, Anne L.; INGRAM, Helen. Policy design for democracy. Lawrence, KS: University of Kansas Press, 1997.

SHAFIQUE, Muhammad. Thinking inside the box? Intellectual structure of the knowledge base of innovation research (1988-2008). Strategic Management Journal, Chichester, v. 34, n. 1, p. 62-93, 2013.

SIDDIKI, Saba. Assessing policy design and interpretation: an institutions-based analysis in the context of aquaculture in Florida and Virginia, United States. Review of Policy Research, [Online], v. 31, n. 4, p. 281-303, 2014. SIDDIKI, Saba. Understanding and analyzing public policy design. Cambridge: Cambridge University Press, 2020.

SLAVIN, Robert E. Best evidence synthesis: an intelligent alternative to meta-analysis. Journal of Clinical Epidemiology, [Online], v. 48, n. 1, p. 9-18, 1995. SNOW, Dave. The social construction of naturopathic medicine in Canadian newspapers. Policy Studies, p. 1-21, 17 dez. 2019.

SNYDER, Hannah. Literature review as a research methodology: an overview and guidelines. Journal of Business Research, Abingdon, v. 104, p. 333 339, nov. 2019.

THALER, Richard H. Misbehaving. 1. ed. Rio de Janeiro: Intrínseca, 2019.

TORRACO, Richard J. Writing integrative literature reviews: guidelines and examples. Human Resource Development Review, Thousand Oaks, v. 4, n. 3, p. 356-367, 24 set. 2005.

TRANFIELD, David; DENYER, David; SMART, Palminder. Towards a methodology for developing evidence-informed management knowledge by means of systematic review. British Journal of Management, Oxford, v. 14, n. 3, p. 207-222, set. 2003.

TURNBULL, Nick. How should we theorise public policy? Problem solving and problematicity. Policy and Society, [Online], v. 25, n. 2, p. 3-22, 2006.

VAN BUUREN, Arwin et al. Improving public policy and administration: exploring the potential of design. Policy \& Politics, [Online], v. 48, n. 1, p. 3-19, 2020. VAN GEET, Marijn Thomas; LENFERINK, Sander; LEENDERTSE, Wim. Policy design dynamics: fitting goals and instruments in transport infrastructure 
planning in the Netherlands. Policy Design and Practice, [Online], v. 2, n. 4, p. 324-358, 2019.

VARGAS, María Helena Franco; RESTREPO, Daniela Roldan. The instruments of public policy. A transdisciplinary look. Cuadernos de Administración, Cali, v. 35, n. 63, p. 101-113, 2019.

VEDUNG, Evert. Six models of evaluation. In: ARARAL, Eduardo et al. (ed.). Routledge Handbook of Public Policy. New York: Routledge, 2015. p. 387-400.

VOSS, Jan-Peter; SIMONS, Arno. Instrument constituencies and the supply side of policy innovation: the social life of emissions trading. Environmental Politics, Essex, v. 23, n. 5, p. 735-754, 2014.

WARD, Vicky; HOUSE, Allan; HAMER, Susan. Developing a framework for transferring knowledge into action: a thematic analysis of the literature. Journal of Health Services Research \& Policy, London, v. 14, n. 3, p. 156164, 11 jul. 2009.

WHICHER, Anna. Evolution of policy labs and use of design for policy in UK government. Policy Design and Practice, [Online], v. 4, n. 2, p. 1-19, 18 mar. 2021.

WILDAVSKY, Aaron. Speaking truth to power: art and craft of policy analysis. 12. ed. New Jersey: Transaction, 2007.

WILSON, James Q. Bureaucracy: what government do and why they do it. 2. ed. Washington: Basic Books, 2000.

WILSON, James Q. Political organizations. New York: Basic Books, 1974. ZHANG, Chao et al. Policy design and social construction amid mass protests: a case study of the response to the Wukan incident. The China Nonprofit Review, [Online], v. 7, n. 1, p. 35-64, 27 maio 2015.

Conectando problemas, soluções e expectativas: mapeando a literatura sobre análise do desenho de políticas públicas

Resumo: O artigo explora e sistematiza a literatura sobre policy design com o objetivo de fornecer um mapa desse subcampo da policy analysis, identificando os temas que recebem mais e menos atenção e debatendo conceitos e perspectivas. Ao final, delineamos uma agenda de pesquisa. Efetuamos uma revisão semissistemática de 74 documentos selecionados por meio da técnica 
snowball sampling. Verificamos que o conceito de desenho abarca os elementos: problemas, objetivos, instrumentos, grupos afetados e resultados, que devem exibir conexão lógica - cada qual movimentando um conjunto de recursos analíticos voltados à compreensão do funcionamento das políticas e da produção de resultados sociais. Uma agenda de pesquisa nacional poderia abordar, por exemplo, processos de transferência de desenhos entre governos e a influência dos órgãos de controle nas preferências por determinados tipos de desenhos.

Palavras-chave: políticas públicas; policy design; instrumentos de políticas públicas; processos decisórios; revisão de literatura.

\section{Connecting problems, solutions, and expectations: mapping the policy design literature}

Abstract: This article explores and systematizes the literature on policy design, aiming to provide a map of this subfield of policy analysis, identify the topics that receive more and less attention, and debate concepts and perspectives. We end by outlining a research agenda. We carried out a semi-systematic review of 74 documents selected using the snowball sampling technique. We found that the design concept includes the following elements: problems, objectives, instruments, target groups, and results. These elements must have a logical connection with one another. Each element employs a set of analytical resources to understand the functioning of policies that produce social results. A national research agenda could address, for example, design transfer processes among governments and the influence control bodies on preferences for certain types of designs.

Keywords: public policy; policy design; instruments; decision-making process; literature review.

\section{Conectando problemas, soluciones y expectativas: mapeo de la literatura sobre el análisis del diseño de políticas públicas}

Resumen: El artículo explora y sistematiza la literatura sobre diseño de políticas, con el objetivo de proveer un mapa de este subcampo del análisis de políticas, identificando los temas que reciben más y menos atención y debatiendo conceptos y perspectivas; al final, delineamos una agenda de investigación. Realizamos una revisión semi-sistemática de 74 documentos seleccionados 
mediante la técnica de muestreo de bola de nieve. Comprobamos que el concepto de diseño engloba los elementos: problemas, objetivos, instrumentos, grupos afectados y resultados, que deben exhibir una conexión lógica. Cada uno utiliza un conjunto de recursos analíticos orientados a comprender el funcionamiento de las políticas y la producción de resultados sociales. Una agenda nacional de investigación podría abordar, por ejemplo: los procesos de transferencia de diseños entre gobiernos y la influencia de los órganos de supervisión en las preferencias por ciertos tipos de diseños.

Palabras clave: política pública; diseño de políticas; instrumentos; proceso de toma de decisiones; revisión de literatura.

Recebido em 18 dezembro de 2020

Aprovado em 28 de maio de 2021. 